
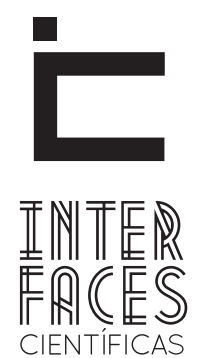

EDUCAÇÃO

ISSN IMPRESSO 2316-333X

ISSN ELETRÔNICO 2316-3828

Artigos de demanda contínua

\title{
BOAS LEITURAS ÀS MULHERES LUSITANAS: O BEIJA-FLOR, JORNAL PORTUGUÊS À BRASILEIRA, DEDICADO À INSTRUÇÃO E RECREAÇÃO.
}

\section{RESUMO}

Este trabalho busca tornar visível a representação de mulher oitocentista no jornal O Beija-Flor, Semanário d'Instrução e Recreio, dedicado às mulheres, o qual veio a lume em Lisboa, em 15 de agosto de 1838, e findou no dia 13 de abril de 1842. Para atingir tal objetivo, buscou-se responder às seguintes questões: quais os gêneros literários mais disseminados nesse periódico? Qual é a representação de mulher divulgada pelo discurso masculino no periódico? Ou que tipo de mulher o periódico buscava formar? Este trabalho está inscrito na abordagem teórico-metodológica da Nova História Cultural, a qual tem considerado os usos da escrita como uma fonte bastante significativa para compreender como comunidades ou indivíduos constroem suas representações de mundo e as investem de significação. Com efeito, em O Beija-Flor há a construção de uma identidade feminina através dos escritos dos homens em difundir, entre as leitoras lusitanas, uma determinada leitura específica voltada para sua formação moral e intelectual, na qual não permite liberdade de ação fora do lar e enaltece as virtudes femininas. A boa leitura, por meio do jornal, deveria oferecer ensinamentos úteis não só às leitoras de forma individual, mas, sobretudo àqueles ou àquelas que tivessem contato com elas.

\section{PALAVRAS-CHAVE}

Jornal. Mulher. Século XIX. 


\section{ABSTRACT}

This paper seeks to make visible the representation of nineteenth-century women on the newspaper $O$ Beija-Flor, Semanário d'Instrução e Recreio dedicated to women, which came to light in Lisbon on August 15, 1838, and ended on April 13, 1842. To achieve this goal, we sought to answer the following questions: which literary genres were more widespread in this periodical? What representation of woman was published by male discourse in the journal? Or what kind of woman the journal sought to form? This work is inscribed in the theoretical and methodological approach of the New Cultural History, which has considered the use of writing as a very significant source for understanding how communities and individuals construct their representations of the world and the significance of investing. Indeed, on $O$ Beija-Flor is the construction of a feminine identity through the writings of men to spread among the Portuguese readers, a certain specific reading toward their moral and intellectual, which does not allow freedom of action outside the home and extols the virtues of female. The good read through the paper, should provide useful lessons to readers not only individually, but especially those or those who had contact with them.

\section{KEY WORDS}

Newspaper. Women. Century XIX.

\section{RESUMEN}

Este trabajo tiene como objetivo hacer visible la representación de las mujeres en el periódico del siglo XIX, El Colibrí, semanal d' Educación y Recreación, dedicado a la mujer, que salió a la luz en Lisboa el 15 de agosto de 1838, y terminó el 13 de abril, 1842. Para lograr este objetivo, hemos tratado de contestar a las siguientes preguntas: ¿cuáles son los géneros literarios más difundidas en esta revista? ¿Cuál es la representación de la mujer por el discurso masculino publicado en la revista? Y aun, se preguntaba, ¿a qué clase de mujer se buscó formar con el periódico? Este trabajo se ha registrado en un enfoque teórico y metodológico de la nueva historia cultural, que ha considerado el uso de la escritura como una fuente muy importante para comprenderse cómo las comunidades o los individuos construyen sus representaciones del mundo e invierten en significado. De hecho, en El Colibrí, se encuentra la construcción de la identidad femenina a través de los escritos de los hombres, donde se difunde entre las lectoras lusitanas, una lectura específica, volcada en su formación moral e intelectual, que no permite la libertad de acción fuera del hogar, y a la vez, ensalza las virtudes femeninas. La buena lectura a través de los periódicos, debería proporcionar lecciones útiles para los lectores no sólo individualmente, sino, sobre todo, a aquellos, o aquellas que tuviesen contacto con ellas.

\section{PALABRAS CLAVE}

Prensa. Mujeres. Siglo XIX. 


\section{INTRODUÇÃO}

O primeiro jornal que surgiu em Portugal foi $A$ Gazeta da Restauração em novembro de 1641, a proclamar a Restauração da Independência. Entre os anos de 1647 a 1663 não houve publicações periódicas em Portugal, sendo mais comuns as publicações volantes, cujas notícias se detinham sobre a guerra da independência entre Portugal e Espanha. Somente em janeiro de 1663 veio a lume o segundo periódico, Mercúrio Português, ao estilo da Gazeta, e circulou até julho de 1667 (TENGARRINHA, 1989).

No século XVIII, o jornalismo português esteve atrasado em relação aos demais países da Europa do Norte e do Centro, em decorrência ao absolutismo régio e à Igreja Católica que impediam a liberdade de imprensa. Entretanto, a imprensa literária se faz presente nesse período, com o seguinte objetivo segundo Pallares-Burke (1996, p. 29), “os periódicos literários do século XVIII tinham o papel privilegiado de colocar em ação um eficiente aparato de mediação, capaz de moldar as mentes e até de influenciar a organização da sociedade"4.

A respeito dos periódicos setencetistas, Sant'Anna (2007, p. 16 - 17) afirma que:

\begin{abstract}
Durante a primeira metade do século XVIII, surgem em Portugal, ao lado dos periódicos jornalísticos, folhetos de conhecimentos gerais e de deleite, dirigidos à burguesia em ascensão. Eram as primeiras manifestações da imprensa literária lusitana que só surgiria a partir da publicação do periódico intitulado Gazeta Literária ou Notícia Exacta dos Principais Escritos que Modernamente Se Vão Publicando na Europa (1761-1762).
\end{abstract}

3 "A primeira gazeta, pois, de que apparece noticia, e a que tem o titulo seguinte: Gazeta em que se relatam as novas todas que houve nesta corte, e que vieram de varias partes no mez de Novembro de 1641. Com todas as licenças necessarias e privilegio real. Em Lisboa, na Offic. de Lourenço de Anvers. 4.․" (Dicionário Bibliográfico Português de Innocêncio Francisco da Silva, s/d). Este periódico circulou até 1647. No entanto, em 1715, há o aparecimento de Gazeta de Lisboa, Lisboa: Officina Pascoal da Sylva, 1715-1833.

4 Apud Claude Labrousse, Pierre Rétat, L'instrument périodique - la function de la presse ou XVIIle siècle. Lyon: Presses Univ. de Lyon, 1985.
Mas a verdadeira implementação da imprensa portuguesa apenas se efetivou no século XIX, em virtude da Revolução Liberal de 1820, cujo movimento anulou a censura e a pressão exercida pelo Estado e pela Inquisição, possibilitando o surgimento da imprensa feminina, surgida em 1807, em Lisboa, com a publicação quinzenal de 0 Correio das Modas $s^{5}$, "com figurinos e secções recreativas, ao elevado preço de 240 réis, de que saíram apenas 5 números" (TENGARRINHA, 1989, p. 54). No entanto, a primeira imprensa feminina europeia é datada do século XVIII, a qual era especializada em moda, a exemplo de "Jornal des dames (1750-1778) e Female Spectator(1774-1746)" (PERROT, 2008, p. 33). Em um breve levantamento sobre os jornais portugueses na Biblioteca Nacional de Portugal, localizam-se outros jornais que circularam em Lisboa e podemos supor terem sido destinados às mulheres apenas pelos títulos, os quais são: O Recreio: jornal das familias (1835-1842); A Abelha: jornal de utilidade, instrucção e recreio (1836); O Ramalhete: jornal d'instrucção e recreio (1837-1844)6.

Entre os jornais acima citados, há O Beija-Flor, Semanário d'Instrução e Recreio ${ }^{7}$, dedicado ao bello sexo, o qual veio a lume em Lisboa, em 15 de agosto de 1838 , e findou no dia 13 de abril de 1842, pela Tipografia de Vieira e Torres, a qual estava localizada na Travessa da Portaria das Freiras de Santa Anna n ${ }^{\circ} 4$ A. Fundado por

5 No Brasil, há os jornais intitulados Correio das Modas (1838-1839) e Novo Correio das Modas (1852-1854), cujas publicações são oriundas do Rio de Janeiro, editados por Eduardo e Henrique Laemmert. 6 O Recreio: jornal das familias. Lisboa: Imprensa Nacional, 1835-1842; A Abelha: jornal de utilidade, instrucção e recreio. [Lisboa: Impr. de C.A.S. Carvalho], 1836; O Ramalhete: jornal d'instrucção e recreio. Lisboa: Imp. de C. A. S. Carvalho, 1837-1844.

7 Esse jornal é apresentado pelo título O Beija-flor: semanario d'informação e recreio. Lisboa: Typ. de Vieira \& Torres, 1838-1842. Nota-se o que distingue é a palavra informação. No jornal analisado aqui, o título de instrucção. 
José Maria da Silva Leal ${ }^{8}$, estando na direção até o ano seguinte, conforme o Dicionário Bibliográphico Portuguez de Innocêncio Francisco da Silva, cujos artigos saíram anônimos ou com as iniciais S. V.

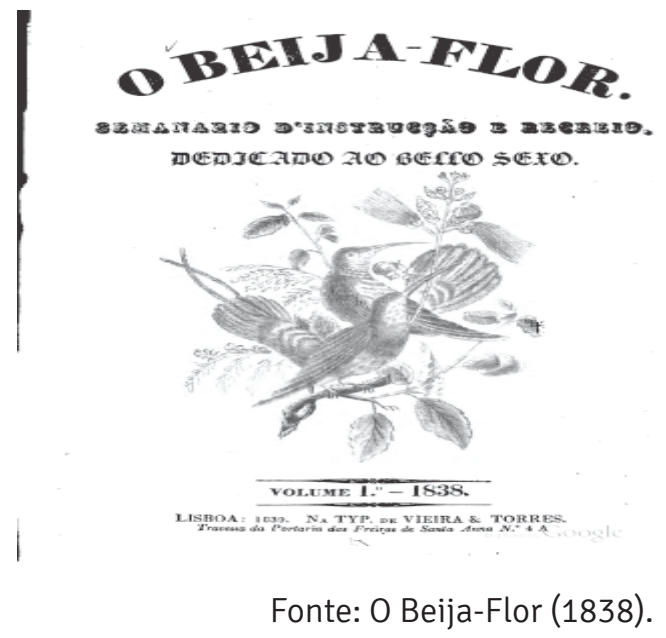

Periódico semanal e ilustrado português, $O$ Beija-Flor circulava com oito páginas, as quais eram compostas de

uma seleção apurada de fatos históricos e histórias galantes e exemplares, ornadas em cada número com uma bela estampa litografada, constituirá a parte principal do Jornal. Algumas vezes Poesia selecta, vários artigos de Recreação das Ciências Variedades, Anedotas, e algumas Charadas.

8 Ainda segundo esse Dicionário, José Maria da Silva Leal também fundou outros periódicos, tais como: A legalidade. A fama. 1843, A illustração, de 1845 para 1846, O oculo. 1847. E dirigiu os seguintes: A Revista universal lisbonense, desde 1841 até 1857, quando o illustre poeta Antonio Feliciano de Castilho deixou esta folha. Ahi os seus artigos eram assignados Silva Leal. - A Revista do conservatorio real de Lisboa, em 1848; a Liga, em 1849; o Bibliophilo, de collaboração com Rodrigo José de Lima Felner, e a introducção, que se attribuiu a este, era só de Silva Leal, e o Boletim de architectura e archeologia, em 1874. Tem n'este ultimo, artigos assignados com as iniciaes S. V., ou anonymos, ou com o anagramma Sá Villela. Colaborou também em: Desengano, em 1830; Ecco, em 18351840; Gazeta de Portugal, em 18351837; Nacional, em 18341842; Correio, em 18361837; Minerva, em 1836; Mosaico, em 18391841, assignando com o nome completo, ou só Silva Leal; RamaIhete, em 18371844; Panorama, em 18371868, assignando Silva Leal; Universo pittoresco, em 18391844; Sentinella do palco, em 1840; EspeIho do palco, em 1842; Pirata, em 1842; Tribuno, em 18431844;
Tendo como público-leitor, a priori, as damas lusitanas, conforme anuncia a capa do jornal, o objetivo desse semanário era instruir e divertir as leitoras, cujo propósito tem origem na máxima de Horácio (65 a. C 8 a. C) em Arte Poética. No prólogo do primeiro número, a virtude e a moral são os horizontes perseguidos pelos redatores:

[...] julgamos proveitoso a redação de um Jornal em que a virtude se avive com exemplos heróicos, em que a moral se desenvolva pura como ela é; um Jornal que apresente todos os rasgos admiráveis, ou sejam tirados dos anais da história, ou criados pela imaginação dos moralistas; um Jornal onde o mago encanto de satisfazer uma curiosidade folgasa [sic] inspire n'alma, quase sem se sentir um sopro de vida pura, abra no coração manancial de virtudes sociais (O BEIJA-FLOR, 1838, p.1).

$\mathrm{Na}$ intenção de conhecer como O Beija-Flor instruía e recreava suas leitoras portuguesas no século XIX, este ensaio torna visível o discurso produzido e divulgado pelos seus redatores direcionado ao sexo feminino e, que, de modo algum pretende ser exaustivo, tendo como referência o seu primeiro ano de circulação, 15 de agosto de 1838 a 26 de dezembro de $1838, n^{\circ} 20$, em virtude da sua disponibilidade digital. De antemão, cabe fazer uma observação, a de que não se está tratando de todas as mulheres portuguesas, mas tão-somente à leitora portuguesa, a qual é a mulher burguesa alfabetizada, que, muitas vezes, viveu num espaço urbano. Entretanto, compreende-se que:

[...] a circulação de palavras - faladas, manuscritas ou impressas - não se fechava em fronteiras sociais e perpassava amplos setores da sociedade [...] e não ficava estanque a um círculo de letrados, embora estes, também tocados por contradições e diferenças, detivessem o poder de produção e leitura direta da imprensa (MOREL, 2009, p. 163).

Nessa perspectiva, buscar-se-á responder às seguintes questões que emergiram ao tratá-lo como objeto e fonte: quais os gêneros literários mais disseminados nesse periódico? Qual é a representação de mulher divulgada pelo discurso masculino no pe- 
riódico? Ou que tipo de mulher o periódico buscava formar? Mas antes de responder às questões, faz-se necessário apresentar a materialidade do jornal que ora examina-se para compreender-se como o texto opera, ou seja, a maneira pela qual ele se apresenta aos leitores e leitoras (DARNTON, 2005). Para tanto,

\section{NAS PÁGINAS D' O BEIJA-FLOR, A SUA MATERIALIDADE}

Compreendendo que não havia originalidade na composição de um jornal, por esse tipo de publicação ter se revelado como um verdadeiro mosaico de informações, no qual se poderia ter origem a mesma fonte (BARBOSA, 2007; PEIXINHO, 2009), os redatores deram a conhecer que o título do periódico se originou de uma ave brasileira, o beija-flor, e explicaram, no prólogo do jornal, o significado que tal ave tinha para este veículo:

\begin{abstract}
O seu mesmo título metaforicamente derivado d'uma ave do Brasil, que voejando de flor em flor delas extrai o mel para o seu sustento, está indicando que ele irá buscar quanto houver de melhor dentro da órbita que se produz girar, qualquer parte que ele exista; e por isso muito estimaria ter correspondentes que the enviassem suas produções quando sejam escritas no sentido do Jornal (O BEIJA-FLOR, 1838, p. 1)
\end{abstract}

Os correspondentes que contribuíram no periódico semanal foram destacados no final da última edição d' O Beija-Flor, sendo intitulados como os "correspondentes da sociedade do Beija-Flor”, são eles:

Bragança: 0 Ilmo Sn. Antonio Caetano d' Oliveira Furtado.= Coimbra: J.M.S. de Paula. = Caminha: Antonio Rodrigues d' Oliveira. = Évora: Antônio Joaquim Álvares. = Figueira: Joaquim Malheiro de Mello = Lagos: Francisco Xavier Baptista $=$ Ponte de Lima: Antonio Caetano Pereira de Lima e Sampaio = Porto: J.M.C Portugal: Francisco de Salles Gomes Cardozo = Santarém: Antonio Gonçalves d'Almeida Rino = Setubal: JC Scotto = Sines: Jerônimo Martins Salgado = Viana do Minho: Antonio Luis Ribeiro da Silva = Vidigueira: Joaquim Ig- este trabalho está inscrito na abordagem teórico-metodológica da Nova História Cultural, a qual tem considerado os usos da escrita como uma fonte bastante significativa para compreender como comunidades ou indivíduos constroem suas representações de mundo e as investem de significação (CHARTIER, 1999). nácio Prego = Viseu: Dionísio de Souza Loureiro = Ithas = Fayal e Terceira: João de Bittencourt Vasconcellos Correa a Ávila (O BEIJA-FLOR, 1838, p.162).

As informações acerca dos correspondentes contribuem para compreender o perfil do próprio jornal. Assim, o trecho acima revela que as colaborações vieram de toda a parte de Portugal, levando-nos a inferir que esse jornal circulou por essas regiões. Ou ainda pode-se entender que diversas pessoas em diferentes lugares de Portugal puderam contribuir para composição desse jornal. Se, por um lado, esses homens de diferentes províncias portuguesas que compuseram essa sociedade mantiveram $O$ Beija-Flor ativo e em circulação, por outro, a identificação deles demonstra quem direcionava a leitura das damas lusitanas.

Embora a relação de correspondentes possa revelar a supremacia escrita masculina sobre as mulheres, dizendo o que elas são ou o que elas deveriam fazer, há a presença de dois textos assinados por mulheres. Um é charada e o outro é poesia, cujos textos são subscritos "Por uma senhora" (O BEIJA-FLOR, p. 64 e 72). Segundo Perrot (2008, p. 31), "as vias escritas para as mulheres no mundo proibido da imprensa foram a religião e o imaginário: as vias místicas e literárias; a oração, a meditação, a poesia e o romance". Entretanto, Pallares-Burke (1996, p. 99) faz o seguinte alerta: "Tanto era usual escritoras esconderem sua identidade optando pelo anonimato ou pelo pseudônimo, muitas vezes masculino, como também era prática comum ho- 
mens de letras se valerem de nomes de mulher". Nessa perspectiva, Barbosa (2007, p. 33) aponta outra justificativa: "uma das razões, a mais óbvia talvez, diz respeito à necessidade de proteção, seja da autoridade, seja da reputação, ou até mesmo, no caso das mulheres, de algum pai ou marido ciumento".

Sob a forma de um livro, O Beija-Flor tem suas páginas enumeradas e divididas em duas colunas, cujas edições subsequentes dão continuidade à numeração, como era comum à época. Assim, no ano de 1838, totalizaram 160 páginas. Nas suas derradeiras páginas, há o "índice das matérias contidas no primeiro volume do Beija-Flor", evidenciando ainda mais o caráter de livro desse periódico semanal. Segundo Lustosa (2004, p. 14), "a maior parte dos jornais da virada do século XVIII para o XIX pouco se parecem com os nossos jornais de hoje".

A presença do índice em $O$ Beija-Flor possibilita à leitora escolher o conteúdo que melhor the convier para a sua leitura, o que implica uma imposição de sentido na prática da leitura desse suporte, já que "as formas materiais afetam os seus sentidos" (CHARTIER, 1999, p. 27). Com esse formato, o jornal, em forma de livro, assumia um importante papel no projeto de instruir e recrear as leitoras, inculcando valores e ideias, por meio de uma leitura aprazível. Sobre esse papel, Lustosa (2004, p. 15) explica:

Num tempo em que o acesso à educação era tão me nos democrático, em que vivíamos a mudança do mundo a partir das idéias disseminadas pelo Iluminismo ao longo do século anterior, a imprensa se firmara como um importante difusor das chamadas Luzes. Naquele contexto, o jornalista se confundia com o educador. Ele via como sua missão suprir a falta de escolas e de livros através dos seus escritos jornalísticos.

A subscrição do jornal português, cuja seção fica na última página, no lado direito inferior, podia ser feita em Lisboa e Coimbra. Para as demais províncias, a assinatura poderia ser feita sob franco de porte, ou seja, sem pagar pelo envio. Observando os números desse jornal, verifica-se que, nos primeiros, a circulação se iniciou pelas cidades supracitadas, ampliando o seu raio de difusão para Porto, Bragança, Viseu, Évora, Vidigueira, Figueira e etc., conforme revela o número 14 , de 14 de novembro de 1838. As assinaturas só poderiam ser realizadas por meio de 12 números ou de forma avulsa, equivalendo a 440 réis e 40 réis, respectivamente, conforme se evidencia na última página do número 11, sob o título "Aos nossos assignantes e leitores” (O BEIJA-FLOR, 1838, p. 88; 96).

Por meio do aviso aos leitores na primeira página d' O Beija-Flor, de 21 de novembro, de número 15, é sabido que os assinantes são de várias províncias. Comumente, os jornais reservavam, ao final da última página de cada edição, um espaço para anúncios e avisos. Em todo o jornal português, testemunha-se apenas um anúncio de venda de livros. Mas quanto aos avisos, esses eram feitos regularmente, os quais anunciavam a história e a estampa do número seguinte.

No que diz respeito às estampas, como são chamadas as ilustrações no interior do jornal, estas se apresentam na capa de cada número do jornal, as quais estão associadas aos textos que são publicados na primeira página. Essas imagens narrativas referemse a um momento preciso que foi representado, cuja função é decorativa, por entender que, ao serem inseridas no jornal, o editor teve ter a pretensão de organizar o conteúdo editorial com o objetivo de promover momentos de descontração no momento inicial da leitura do jornal e antecipando a leitura da história que o jornal narra às leitoras. Mesmo com esse suposto objetivo, as "imagens são feitas para comunicar" e elas "frequentemente despertam emoções bem como veiculam mensagens no estrito sentido do termo" (BURKE, 2004, p. 43; 52).

As ilustrações estão em forma de paisagem, sendo oposta a paginação do restante do jornal, o qual está na forma de retrato. Abaixo das ilustrações há o nome Legrand, o qual está posicionado no canto esquerdo, e no canto oposto está o nome Lith de Lence, 
o que pode-se compreender como identificação das imagens. Outro dado importante que as ilustrações revelam é que são imagens em ação ou em movimento. Segundo Burke (2004, p. 182), "imagens (imagens únicas e em ação) desse tipo eram, de certa forma, agentes históricos, uma vez que não apenas registravam acontecimentos, mas, também, influenciavam a maneira como eles eram vistos na época".

Outro aspecto que decorre da ilustração presente em $O$ Beija-Flor é a ornamentação. Fittipaldi (2008, p. 114) alerta que "padrões ornamentais são formalizações que podem tornar-se convencionais dentro de um sistema cultural: frisos gregos, pinturas corporais indígenas, arte plumária, desenhos de trançados ou tramas de tecidos". Pensar a presença de frisos no jornal, mas não os gregos, que estão

\section{A REPRESENTACÃO DA MULHER PORTUGUESA NO JORNAL: OS GÊNNEROS LITERÁRIOSE TEXTUAIS COMO INSTRUMENTO DE INSTRUÇ̃̃O E RECREAÇ̃̃O}

Instrução e recreação são palavras de ordem nos escritos d' O Beija-Flor, Semanário d'Instrução e Recreio, conforme o próprio subtítulo do jornal evidencia, definindo, assim, as suas características de conteúdo e de objetivo. Nesse periódico português, há a presença de diversos gêneros textuais, tais como charadas, anedotas, poesias, máximas e histórias de modo geral. Enquanto uns gêneros distraiam, outros instruíam as mulheres. Por exemplo, as anedotas, as charadas e as poesias tinham a função de recreá-las, conforme se pode observar a figura 6 acima. Já as máximas, as histórias exemplares e outros textos tinham o caráter de orientar e instruir as leitoras lusitanas. A junção entre literatura e textos instrutivos nos jornais femininos, segundo Buitoni (2009, p. 29) “já nasceu complementar, revestido de um caráter secundário, em toda sua parte, cujos ornamentos separam os textos nesse suporte escrito, conforme pode-se constatar nas colunas d' O Beija-Flor, evidencia que o próprio jornal se configura como uma imagem dirigida às mulheres: atrativa e agradável, favorecendo uma leitura prazerosa. Ainda segundo a autora, (FITTIPALDI, p. 114) "a intenção de ornar e decorar, entre outras funções da ilustração, contribui para a qualidade da forma e da composição, uma qualidade do visível [...]".

Diante da materialidade aqui apresentada do jornal $O$ Beija-Flor, percebe-se que, mesmo que haja uma imposição de sentido para ler esse periódico, "o texto só tem sentido graças a seus leitores; muda com eles; ordena-se conforme códigos de percepção que lhe escapam" (CERTEAU, 1994, p. 266).

tendo como função o entretenimento e, no máximo, um utilitarismo prático ou didático".

A apropriação de diversos gêneros textuais e sua transposição ao suporte do jornal feita pelos editores e redatores permite uma "produção de sentidos pelo leitor e, essa transformação na forma e no suporte, propicia a criação de um novo público, novas formas de leitura e de novos usos para os textos" (CHARTIER, 1999, p. 22). Nesse sentido, Jinzenji (2009, s/p) afirma que:

Os jornais promovem a ampliação do acesso a determinados tipos de impresso e textos, até então restritos aos proprietários de livros e aos assinantes de jornais de outras localidades; nesse processo, disponibilizam e difundem esses textos a um número maior de leitores 
e ouvintes, ou a um público para o qual esses textos não haviam sido destinados inicialmente.

Pelas páginas desse semanário português feminino, atenta-se para as instruções e orientações que foram dadas às lusitanas para serem mulheres prendadas, a exemplo da "Carta de Fr. Luiz de Souza a uma Senhora", "Nova maneira de fazer cahir a ferragem" e Mordidellas d'abelhas e Bespas....", sendo esse último extraído do jornal francês Connaissances-utiles, de 1833. Nesses textos, pode-se observar o papel destinado à mulher, a da leitora utilitária e da cuidadora do lar. No que diz respeito a esse tipo de leitura, esta deve ser restrita, limitando-se a religiosidade, moralidade e civilidade. No trecho da figura 7 , o remetente da carta elaborou e publicou o ABC solicitado pela senhora para aprender a ler. Segundo o Fr. Luiz de Souza, o signatário, define o papel e o perfil da mulher portuguesa, segundo o seu $A B C$ :

A, quer dizer, que seja amiga de sua casa. B, bemquista da visinhança. C, caridosa com os pobres. D, Devota da Virgem. E, entendida em seu officio. F, firme na fé. G, guardadeira de sua fazenda. $\mathrm{H}$, humilde a seu marido. $\mathrm{O}$, inimiga de mexericos. L, leal. $\mathrm{M}$, mansa. $\mathrm{N}$, nobre. $\mathrm{O}$, onesta. P, prudente. Q, quieta. $\mathrm{R}$, regrada. S, sisuda. T, trabalhadeira. V, virtuosa. X, xptâ (christã). Z, zelosa da honra (BEIJA-FLOR, 1838, p. 22).

No que tange ao papel da mulher como a cuidadora do lar, conforme nos textos "Nova maneira de fazer cahir a ferragem" e Mordidellas d'abelhas e Bespas....", o modo de vida da mulher se dava no espaço da casa, cuja função era a manutenção da família, por meio dos trabalhos domésticos, que incluíam a alimentação, o aquecimento, a conservação da casa e da roupa, o transporte de água e etc. (PERROT, 1988).

As narrativas publicadas nos diversos números do jornal O Beija-Flor ao longo do ano de 1838 como, "Esposa na adversidade", "Os fatais efeitos de uma precipitação”, “Uma heróica mulher”, “Ensaio sobre o amor", "Ensaio sobre a moda”, "O perigo das paixões" difundiam os bons costumes que uma mulher deveria ter na sociedade, ou seja, a construção e/ou fortale- cimento da identidade da mulher portuguesa se dava com referência exclusiva ao domínio familiar doméstico. De acordo Outeirinho (s/d, p. 149), que aborda o papel da mulher portuguesa nas obras de Ramalho Ortigão,

\begin{abstract}
A circunscrição de limites físicos e de papéis particulares relativos à mulher faz da casa, do espaço interior do lar, o raio de acção em que ela se move. Efectivamente, a ela competem os deveres domésticos que permitirão um funcionamento harmonioso da família, na medida em que pela especificidade feminina - sensibilidade, fragilidade e susceptibilidade - ela apenas poderá contribuir num trabalho de retaguarda, imprescindível no entanto, como adjuvante discreta do sustentáculo familiar que é o chefe de família [...].
\end{abstract}

Quanto ao gênero literário mais disseminado nesse periódico, a seção de variedades apresenta a maior quantidade de textos em prosa, conforme pode-se observar o índice das matérias publicadas nos jornais, figuras 10 e 11, a seguir. Isso permite inferir sobre o papel principal do jornal português, que é ser o instrumento educativo. Os textos de cunho literário-instrutivo publicados em $O$ Beija-Flor estavam direcionados para a formação do gosto da leitora lusitana, por isso a presença de romances ilustrados (as figuras remetiam aos romances como já se mencionou no tópico anterior), configurando-se como guia de conduta.

Os objetivos moralizantes e educativos presentes explicitamente no projeto editorial das publicações ilustradas do período deveriam ser atingidos por meio de narrativas, numa clara manutenção dos costumes que cabiam à mulher lusitana, ratificando o lugar dela na sociedade, conforme observa-se pelos textos presentes nesse jornal.

Monteiro (1998, p. 62) apresenta o papel da mulher no século XIX, por meio da obra de Willian Acton, The Functions and Disorders of the Reproductive Organs, no qual afirma que "as únicas paixões sentidas pelas mulheres eram pelo lar, filhos e dever domésticos”. Já em o Código do Bom-Tom, ou Regras da civilidade e de bem viver no século XIX (1845) do português J.I. 
Roquette são arrolados os comportamentos distintos para as meninas e meninos, preparando-os para a vida em sociedade. Nesse opúsculo, o autor orienta o conteúdo das conversas, as pessoas com quem se devem conversar, as roupas apropriadas para diversas ocasiões e etc., para ambos os sexos, sendo para a mulher as orientações mais cautelosas.

Publicações portuguesas anteriores ao século XIX já ratificavam o papel da mulher na sociedade, a exemplo de Carta de Guia de Casados (1651) da autoria de D. Francisco Manoel, o qual aconselha os homens a se casarem com mulheres virtuosas, justificando e orientando como torná-las ainda mais virtuosas, e Cartas sobre a educação da mocidade (1759) de Ribeiro Sanches, que em uma das suas seções, prescreve as orientações das consequências negativas para as mães por não criarem seus filhos. Para tanto, nos textos publicados em $O$ Beija-Flor, há sedimentada a imagem da mulher maternal, virtuosa e prendada, sendo um apanágio da visão masculina, por terem sido eles os correspondentes desse jornal.

\section{CONCLUSÃO}

A imprensa de um modo geral, e em especial, a feminina, possibilita o conhecimento da história das mulheres portuguesas. 0 jornal como objeto e como fonte de pesquisa favorece compreender o cotidiano de um determinado espaço e público, onde tal suporte está inserido, bem como apresenta vestígios sobre as suas relações com as instâncias de poder.

Ao tratar da representação da figura feminina lusitana no jornal $O$ Beija-Flor, percebe-se como esse periódico projetou a identidade da mulher, por meio das narrativas construídas pela imaginação masculina, a qual se deu em processos definidos histórica e culturalmente. Nesta perspectiva,

\section{assume-se que as práticas sociais de representação vigentes em uma certa época estão cristalizadas em formas textuais e que é possível associar as represen- tações às ordens de discurso a que estão genealogi- camente relacionadas e também a outros discursos (FERREIRA, 2003, p. 767).}

O jornal aqui estudado se configura como uma espécie de "museus de tudo", segundo Pecheman, (2002), ao se referir aos jornais femininos, oferecendo às leitoras lusitanas instruções ao mesmo tempo em que as divertiam. Esse tipo de leitura, o qual unia o útil e o agradável, teve o objetivo de instruí-las sem que esta fosse cansativa. Para cumprir o papel de ensinar um conjunto de regras indispensáveis para o bom desempenho da mulher na vida social, o jornal serviu como um instrumento importante para educar, até porque poderia ser lido por muitos. Nessa perspectiva, cabe corrobor com Pallares-Burke (1996, p. 9), quando afirma que "a imprensa periódica mobiliza opinião, propaga ideias e é agente de educação que objetiva influenciar o público". A finalidade do jornal dedicado ao bello sexo é o cultivo da virtude, da moral, da obediência, da docilidade e das atividades domésticas através de uma literatura prescritiva, com caráter pedagógico para a formação da mulher lusitana.

Com efeito, em $O$ Beija-Flor, pode-se perceber a construção de uma identidade feminina por meio dos escritos dos homens em difundir, entre as leitoras lusitanas, uma determinada leitura específica voltada para sua formação moral e intelectual, na qual não permite liberdade de ação fora do lar e enaltece as virtudes femininas. De modo que a boa leitura deveria oferecer ensinamentos úteis não só às leitoras de forma individual, mas, sobretudo àqueles ou àquelas que tivessem contato com elas, pois era por meio delas que essa virtude seria estendida a toda a sociedade portuguesa. 


\section{REFERÊNCIAS}

BARBOSA, S. de F. P. Jornal e Literatura: a imprensa brasileira no século XIX. Porto Alegre: Nova Prova, 2007.

BUITONI, D. H. S. Mulher de papel: a representação da mulher pela imprensa feminina brasileira. São Paulo: Summus, 2009.

BURKE, P. Testemunha ocular: história e imagem. Trad. Vera Maria Xavier dos Santos. Bauru, SP: EDUSC, 2004.

CERTEAU, M. A invenção do cotidiano: 1 . Arte de fazer. Trad. Ephraim Ferreira Alves. 5. Ed. Petrópolis, RJ: Vozes, 1994

CHARTIER, R. (1999) A ordem dos livros: leitores, autores e bibliotecas na Europa entre os séculos XIV e XVIII. Trad. Mary Del Priore. 2. ed. Brasília/DF: UnB.

DARNTON, R. As notícias em Paris: uma pioneira sociedade de informação. In: Os dentes falsos de George Washington. Um guia não convencional para o século XVIII. São Paulo: Companhia das Letras, 2005.

BIBLIOGRÁFICO PORTUGUÊS. Estudos de Innocencio Francisco da Silva aplicaveis a Portugal e ao Brasil. Continuados e ampliados por P. V. Brito Aranha. Revistos por Gomes de Brito e Álvaro Neves, Lisboa: Imprensa Nacional, v. 23, 1858-1923.

FERREIRA, L. M. A. (2003) A construção discursiva das identidades femininas na imprensa brasileira do início século XIX. Anais do $5^{\circ}$ Encontro do Celsul, Curitiba-PR, 2003.

FITTIPALDI, C. O que é uma imagem narrativa? In: OLIVERIA, leda de. $\mathbf{O}$ que é qualidade em ilustração no livro infantil e juvenil: com a palavra o ilustrador. São Paulo: DCL, 2008.
FRANCISCO MANUEL. Carta de guia de casados. Londres. Oficina de T. C. Hansard, Peterboro, Court, FleetStreet, 1820.

JINZENJI, M. Y. (2009). A instrução e educação das senhoras brasileiras do século XIX através do periódico 0 Mentor das Brasileiras. Texto impresso, 2009.

LUSTOSA, I. 0 nascimento da imprensa brasileira. 2. ed. Rio de Janeiro: Jorge Zahar Editor, 2004.

MONTEIRO, M. C. (1998) Figuras errantes na época vitoriana: a preceptora, a prostituta e a louca. In: Fragmentos, v. 8, n. 1, p. 61/71 Florianópolis/ jul - dez/.

MOREL, M. Da gazeta tradicional aos jornais de opinião: metamorfoses da imprensa periódica no Brasil. In: NEVES, Lúcia Maria B. P. das (org.). Livros e impressos: retratos do Setecentos e do Oitocentos. Rio de Janeiro: EdUERJ, 2009.

PEIXINHO, A. T. O Epistolar como modo comunicacional da imprensa de opinião no século XIX. In: $\mathbf{6}^{\circ}$ Congresso SOPCOM. 14 a 18 de abril de 2009. Disponível em: <http://conferencias.ulusofona.pt/index. php/sopcom_iberico/sopcom_iberico09/schedConf/ presentations?searchField=1HYPERLINK "http://conferencias.ulusofona.pt/index.php/sopcom_iberico/ sopcom_iberico09/schedConf/presentations?search Field $=1$ \&searchMatch=contains\&search=peixinho\&t rack=19"\&HYPERLINK “http://conferencias.ulusofona.pt/index.php/sopcom_iberico/sopcom_iberico09/ schedConf/presentations?searchField=1\&searchMat $c h=$ contains\&search=peixinho\&track=19"searchMatc $\mathrm{h}=$ containsHYPERLINK "http://conferencias.ulusofona.pt/index.php/sopcom_iberico/sopcom_iberico09/ schedConf/presentations? searchField=1\&searchMa $\mathrm{tch}=$ contains\&search=peixinho\&track=19"\&HYPER LINK "http://conferencias.ulusofona.pt/index.php/ sopcom_iberico/sopcom_iberico09/schedConf/pre 
sentations?searchField=1\&searchMatch=contains\& search=peixinho\&track=19"search=peixinhoHYPER LINK “http://conferencias.ulusofona.pt/index.php/ sopcom_iberico/sopcom_iberico09/schedConf/pres entations?searchField=1\&searchMatch=contains\&s earch=peixinho\&track=19"\&HYPERLINK “http://conferencias.ulusofona.pt/index.php/sopcom_iberico/ sopcom_iberico09/schedConf/presentations?searchF ield=1\&searchMatch=contains\&search=peixinho\&tra ck=19"track=19>. Acesso em: 15 fev. 2010.

PERROT, M. Os excluídos da história: operários, mulheres e prisioneiros. Trad. Denise Bottmann. Rio de Janeiro: Paz e Terra, 1988.

PERROT, M. Minha história das mulheres. Trad. Angela M. S. Corrêa. São Paulo: Contexto, 2008.

O BEIJA-FLOR. Semanário d'Instrução e Recreio, dedicado ao bello sexo. Lisboa, 15 de agosto a 26 de dezembro de 1838.

OUTEIRINHO, F. (2011). A mulher: educação e leituras francesas na crônica de Ramalho Ortigão. Disponível em: <http://repositorio-aberto.up.pt/handle/10216/9210>. Acesso em: 15 mar. 2011.
PALLARES-BURKE, M. L. G. Nísia Floresta: o Carapuceiro e outros ensaios de tradução cultural. São Paulo: Hucitec, 1996.

PECHMAN, R. M. Cidades estreitamente vigiadas: 0 detetive e o urbanista. Rio de Janeiro: Casa da Palavra, 2002.

ROQUETTE, J. I. Código o Bom-Tom, ou, Regras da Civilidade e de Bem Viver no Século XIX. In: SCHWARCZ, Lilia Moritz (org.). São Paulo: Companhia das Letras, 1997.

SANCHES, A. R. Cartas sobre a Educação da Mocidade. Universidade da Beira Interior. Covilhã/Portugal, 2003.

SANT'ANNA, B. de C. L. Portugal e Brasil: a imprensa literária e o início da imprensa ilustrada. Patrimônio e Memória. UNESP - FCLAs - CEDAP, v. 3, n. 2, 2007, p. 1.

TENGARRINHA, J. História da imprensa periódica portuguesa. 2. ed., edição revista e aumentada. Lisboa: Editorial Caminho, 1998.
Recebido em: 3 de Outubro de 2013 Avaliado em: 19 de novembro de 2013 Aceito em: 2 de Dezembro de 2013
1 Pós-doutor em Educação pela UNICAMP, professor associado no Departamento de Metodologia de Educação da Universidade Federal da Paraíba. Atua no Programa de Pós-Graduação em Educação. E-mail: charlitonlara@ yahoo.com.br.

2 Pós-doutora em Educação pela UERJ, professora adjunta no Departamento de Metodologia de Educação da Universidade Federal da Paraíba. Atua no Programa de Pós-Graduação em Educação. Endereço: Rua Oceano Pacífico, 1228, AP. 401, Intermares- Cabedelo/PB CEP: 58310-000. E-mail: fabianasena@yahoo.com.br 
